Rev. Biol. Trop. 46(4): 1199-1200, 1998

www.ucr.ac.cr www.ots.ac.cr www.ots.duke.edu

\title{
AMPLIACION DE AMBITO
}

\section{Presence of the White-fronted Woodpecker Melanerpes cactorum (Piciformes: Picidae) in the northern Pantanal, Mato Grosso State, Brazil}

Received 7-VIII-1998. Accepted 25-VIII-1998

The species is known to occur in Uruguay, Argentina, Paraguay, Bolivia, Peru and southwestern Brazil. Published records from Brazil are restricted to Miranda (ca. $20^{\circ} 14^{\prime}$ S, 56 $22^{\prime}$ W), Mato Grosso do Sul State, extreme southern part of the Pantanal. In June 1992, July 1996 and January 1997, one to three individuals were seen $c a .400 \mathrm{~km}$ northward, at Santa Inês Ranch (ca. 16 $6^{\circ} 30^{\prime}$ S, $\left.56^{\circ} 45^{\prime} \mathrm{W}\right)$, Poconé municipality, Mato Grosso State. References: Lago-Paiva, C. \& E.O. Willis. 1994. New occurrences of Melanerpes cactorum (D'Orbigny, 1840) (Aves, Picidae) in Brazilian territory. Biotemas 7(1/2): 110-115; Sick., H. 1997. Ornitologia Brasileira. Nova Fronteira, Rio de Janeiro. 912 p.; Yamashita, C. \& V.K. Lo. 1995. Ninhos cooperativos em Melanerpes flavifrons e $M$. cactorum (Piciformes: Picidae). Ararajuba 3: 56-57.

\section{Christine Strussmann}

Rua Antonio Dorileo 508/34, Bairro COOPHEMA, 78085-600 Cuiabá, Mato Grosso, Brazil.

\author{
Ampliación del ámbito de Squilla \\ aculeata (Crustacea: Stomatopoda) \\ en la costa oeste del golfo de \\ California, México
}

\author{
Recibido 23-X-1997. Corregido 10-V-1998 \\ Aceptado 13-V-1998
}

Debido a su alta diversidad los estomatópodos forman un grupo importante de la fauna carcinológica. Su papel dentro de la cadena trófica béntica es también fundamental por ser depredadores activos, así como alimento de otros animales marinos. Pueden ser potencialmente explotables para consumo humano, pues en varias regiones del mundo se les captura para alimento. En México existen especies con buena talla que, sin embargo, son escasamente aprovechadas para consumo local o elaboración de artesanías (Hendrickx y Salgado-Barragán 1991). Los estomatópodos son comunes en la fauna de acompañamiento de la pesca de camarón (Hendrickx 1985), como el caso de este ejemplar que fue obtenido durante un arrastre camaronero nocturno afuera de la bahía Concepción, Baja California Sur. Abreviaturas utilizadas: LT: longitud total, LC: longitud del caparazón, Ac: anchura de la cornea, Lr: longitud de la placa rostral, Lt: longitud de telson, At: anchura del telson. 
Familia Squillidae

Squilla aculeata aculeata Bigelow 1893

Registros previos: Costas de Sinaloa y Oaxaca, México, Pacífico centroamericano y en Iquique, Chile (Reaka y Manning 1980: 17, Hendrickx 1985, Hendrickx y SalgadoBarragán 1991: 97)

Nuevo registro: 1 macho (LT $87 \mathrm{~mm}, \mathrm{LC}$ $20 \mathrm{~mm}$, Ac $5 \mathrm{~mm}$, Lr 3.5, Lt $16 \mathrm{~mm}$, At 18 $\mathrm{mm}$ ), recolectado el 4 de mayo de 1990, en la boca de bahía Concepción, municipio de Mulegé (265' $\left.30^{\prime \prime} \mathrm{N}, 111^{\circ} 55^{\prime} \mathrm{W}\right)$. Recolector: J.R. Bastida-Zavala. Número de catálogo: CINAM-SQUI-000001.

Hábitat: En fondo fangoso a $10 \mathrm{~m}$ de profundidad. Fauna acompañante: el poliqueto terebélido Pista elongata Moore 1909, camarones del género Sicyonia, cangrejos ermitaños y el estomatópodo Hemisquilla ensigera califormiensis Stephenson 1967.

Observaciones: Hendrickx y SalgadoBarragán (1991) consideran a esta subespecie como rara, debido a los pocos ejemplares recolectados. Reaka y Manning (1980), por su parte, mencionan que la subespecie del Atlántico, S. aculeata calmani Holthuis 1959, se presenta en o cerca de las bocas de ríos, como también parece ser el caso de $S$. aculeata aculeata, pues el río Mulegé desemboca a pocos kilómetros del sitio de recolección. El ámbito geográfico de este estomatópodo se extiende hacia el norte desde Topolobampo, Sinaloa, hasta bahía Concepción, Baja California Sur, dentro del golfo de California (ca. de 175 km en línea recta).

\section{REFERENCIAS}

Hendrickx, M.E. 1985. Diversidad de los macroinvertebrados bentónicos acompañantes del camarón en el área del Golfo de California y su importancia como recurso potencial. p. 95-148. In Yáñez-Arancibia, A. (ed.). Recursos pesqueros potenciales de México: La pesca acompañante del camarón. Progr. Univ. de alimentos, Inst. Cienc. Mar Limnol. UNAM, Inst. Nal. Pesca. México, D.F.

Hendrickx, M.E. \& J. Salgado-Barragán. 1991. Los estomatópodos (Crustacea: Hoplocarida) del Pacífico Mexicano. Inst. Cienc. Mar Linmol. UNAM, Publ. Esp. 10(1): 1-200.

Reaka, M.L. \& R.B. Manning. 1980. The distributional ecology and zoogeographical relationships of stomatopod crustacea from Pacific Costa Rica. Smith. Contr. Mar. Sci. (7): 1-29.

María del Socorro García-Madrigal Consultoría e Investigación Ambiental, A.C. (CINAM), Apartado Postal 1-278, Morelia, 58000, Michoacán, México. 